\begin{tabular}{c} 
International Journal of Dental Research, $4(2)(2016) 25-29$ \\
International Journal of Dental Research \\
Website: $\begin{array}{c}\text { ww. sciencepubco.com/index.php/IJDR } \\
\text { doi: } 10.14419 / \text { ijdr.v4i2.6283 } \\
\text { Research paper }\end{array}$ \\
\hline
\end{tabular}

\title{
Mucoadhesive Systems in Dentistry: A Review
}

\author{
Rishi Rath $^{1}$, SiddharthTevatia $^{2 *}$, AnukritiRath $^{3}$, AshishBehl $^{4}$, Vishal Modgil $^{5}$, Nikhil Sharma $^{6}$ \\ ${ }^{1}$ Professor\& Head, Department of Pharmacology, ITS-CDSR Ghaziabad \\ ${ }^{2}$ Post Graduate Student, Department of Periodontology \& Oral Implantology, ITS-CDSR, Ghaziabad \\ ${ }^{3} U G$ Student, ITS-CDSR Ghaziabad \\ ${ }^{4}$ Professor\& Head, Department of Physiology, ITS-CDSR Ghaziabad \\ ${ }^{5}$ Professor\& Head, Department of Human Anatomy, ITS-CDSR Ghaziabad \\ ${ }^{6}$ Professor, Department of Periodontology \& Oral Implantology, ITS-CDSR, Ghaziabad \\ *Corresponding author E-mail:dr.siddharthtevatia@gmail.com
}

\begin{abstract}
For any treatment plan to succeed, two factors are paramount correct selection and application of pharmacologic agents and patient compliance. But what happens when both these are followed judiciously, but the medicine itself does not stay long enough to finish its action? Then we need something that will make the medicine stick literally. That is when bioadhesives have their say. Long-term adhesion of drugs to the oral mucosa is usually prevented by the continuous salivary flow and the mechanical movements of the tongue. Therefore, formulations acting as vehicle for local drug delivery to the oral mucosa need to have excellent mucoadhesive properties. The present article reviews mucoadhesive systems with various formulations that can be used in dentistry to improve local drug delivery.
\end{abstract}

Keywords : Adhesion;bioadhesive;localdrugdelivery;mucoadhesive;vehicle

\section{Introduction}

Physicists define 'Adhesion' as the 'the molecular force of attraction in the area of contact between the unlike bodies that act to hold them together and 'Bioadhesion' as simply 'the adhesive phenomenon. Where at least one of the adherents is biological, such as mucosal membranes. The materials are attached to each other by interfacial forces for an 'extended' period of time. Bioadhesive systems have been used for many years in dentistry in forms of: denture adhesives, stoma based adhesives and also in surgical procedures as surgical glue. The term bioadhesion has also been used to describe adhesive phenomenon related to the ability of some non-biologic macro-molecules and hydrocolloids to adhere to biological tissue for therapeutic purposes in medicine. Adhesion of bioadhesive drug delivery devices to mucosal membranes leads to an increased drug concentration gradient at the absorption site and therefore an improved bioavailability of systemically delivered drugs. (Stephen et al. 1997) 'Mucoadhesion' is a term therefore used for the bioadhesion phenomenon where the biological substrate is a mucosal surface. (Smart 2005)

Mucoadhesives are hydrophilic macromolecules containing numerous hydrogen bond forming groups. They bind to the mucin layer of a biological membrane making its use for therapeutic purposes, especially delivery formulations targeting specific sites like eyes, oral cavity, gastrointestinal tract and vagina. (Batchelor 2004).

\section{Need for the development of mucoadhesives}

The local treatment of oro-mucosal diseases is usually unsatisfactory, because the drug may not stay at the site of action long enough for the desired effect. This long-term adhesion of drugs to the oral mucosa is normally prevented by the continuous salivary flow and the mechanical movements of the tongue. Therefore, formulations acting as vehicle for local drug delivery to the oral mucosa need to have excellent mucoadhesive properties.(Petelin et al. 2004)Mucoadhesive formulations were developed to target local disorders at the mucosal surface (eg. mouth ulcers) to reduce the overall dosage required and minimize the side effects that may be caused by systemic administration of drugs. Hence, mucoadhesives primarily increase the concentration gradient at the site, leading to a sustained release of the local drug. (Batchelor 2004).

A pioneering effort was made in 1947 when penicillin administration to the oral mucosa was achieved by mixing gum tragacant $0 \mathrm{~h}$ with dental adhesive powder. This was eventually to become OrabaseK. (Scrivener \&Schantz 1947) In general medicine, bioadhesive drug delivery systems is quite an established phenomenon however, in dentistry the concept of local drug delivery system is yet to be explored

\section{Materials and methods}

Articles from Pubmed and Medline were searched with mesh adings Adhesion, Adhesion \& Dental, Adhesion and Oral Adhesion and Bioadhesion, Mucoadhesion, Mucoadhesives, and Bioadhesives.

A number of articles appeared but the majority were irrelevant to dentistry, so limits were assigned to select the articles that appeared in dental journals. Time search limit was set from 1965 to till date. Search engine retrieved 28 articles with abstracts ranging from 1991-2016; out of which one was from veterinary dental journal. Full text articles were then located and reviewed, but the authors found a deficiency so a further search was carried out using google search engine and relevant library text were located for completeness of the subject. 
The present article focuses on oral mucosal properties for drug delivery, mechanism of mucoadhesion, ideal requirement of mucoadhesive agents, different mucoadhesive agents and formulations available in market, applications of these mucoadhesive agents in dentistry.

\section{Overview of the oral mucosa}

One of the characteristics of the oral mucosa is its quality of selective permeability, which can be used for local or systemic drug delivery. (Wodley 2001)The permeability barrier of the oral mucous membrane is a result of inter-cellular material derived from the 'membrane coating granules' (MCG). (Gandhi \& Robinson 1994) The non-keratinized epithelium of the buccal mucosa has mainly polar lipids (cholesterol sulphate and glucosylceramides) making it more permeable than keratinized mucosa. (Squier\& Hall 1984)Hence the buccal mucosa and sublingual mucosa are important sites for delivery.(Wertz \&Squier 1991)The MCG of keratinized mucosa contain mainly non-polar lipids e.g. ceramides and acylceramides and these are associated with barrier function, hence relatively impermeable to water.(Squier1991, Wertz 1991,Squier 1996) The oral cavity is coated with molecules of salivary mucins which are major molecules of mucous secretions playing an important role in mucoadhesion and are responsible for the secretory visco-elastic properties. They are negatively charged and are good recipients for drug delivery as they can be molecules and targeted to conjugated to the positively charged drug the respective tissues. The molecular bridge which results between the mucin polymer interpenetration accounts for the adhesive strength. The electronic properties of the mucin also help in mucoadhesion. Mucin therefore has high potential as a pharmaceutical excipient if adequately harnessed. (Adikwu2006).

\section{Mechanism of mucoadhesion}

Many theories have been proposed to describe mucoadhesion, namely Diffusion Theory, Electronic Theory, Adsorption Theory, Wetting Theory, and Fracture Theory. Mucoadhesion is believed to occur in three stages: wetting, interpenetration and mechanical interlocking between the mucin and polymer. However, there is yet to be a clear explanation; as ioadhesion occurs between inherently different mucosal surfaces and formulations. It is unlikely that a single, universal theory will account for $r$ all types of adhesion observed.

The first step is to establish an intimate contact between the adhesive and the substrate (mucous). This is a pre-requisite for mucoadhesion. It is followed by a physical or a mechanical bond formation obtained by deposition and inclusion of an adhesive material in the crevices of mucous and chain entanglement between polymer chains of both phases also referred to as inter-diffusion. (Stephen et al. 1999).

According to the Electronic theory, mucoadhesion occurs from the formation of an electric double layer at the mucoadhesive interface by the transfer of electrons between the mucoadhesive polymer and the mucin glycoprotein network. The Adsorption theory states that mucoadhesive systems adhere to tissues through secondary molecular interactions such as van der Waals forces and hydrogen bonding. (Bhaskara et al. 2003).

Bioadhesive formulations use polymers as the adhesive component. These polymers are often water-soluble and when used in the dry form, they attract water from the mucosal surface and this water transfer leads to a strong interaction. These polymers also form viscous liquids when hydrated with water that increases their retention time over mucosal surface and may lead to adhesive interactions. (Batchelor 2004).

Hydrogels (e.g. natural gums and cellulose derivatives), are hydrophilic matrices which when placed in aqueous media, swell on of water. They are crosslinked and hence do not dissolve in media. When drugs are loaded into these hydrogels as water is absorbed into matrix, chain 'relaxation' occurs and drug molecules are re- leased through spaces or channels in the hydrogel network. (Petelin 2004).

\section{Prerequisites of mucoadhesives}

A complete bioadhesive system would be successful only when it possess certain physiochemical feature including hydrophilicity, numerous hydrogen bond-forming groups, flexibility for interpenetration with both mucus and epithelial tissue and visco-elastic properties upon hydration. (Batchelor 2004) Non toxicity without any undesirable physiological or pharmacological actions and also, most importantly, be non-expensive are some other consideration. (Stephen et al. 1999) An ideal buccal device should be elastic, soft, and able to withstand breakage caused by stress from mouth activities. It must primarily have bioadhesive properties to ensure that it is retained in the mouth for the required period of time. (Mizrahi et al. 2004)

Mucoadhesion is influenced by drug and added excipient and concentration of polymeric compounds. Increase in the concentration of polymeric components significantly enhances formulation compressibility, adhesiveness, mucoadhesion and syringibility. But with increase in the polymeric component, the drug delivery significantly decreases. The other properties at molecular level include charge, hydrogen bonding, hydrophobicity, ability to overcome stearic hindrance problems and lax- weight distribution. The environmental factors influencing mucoadhesion are solubility, $\mathrm{pH}$, ionic strength, presence of other salts and other macromolecules (antibodies, enzymes, polysaccharides etc).(Stephen et al. 1996)

\section{Formulations}

Various bioadhesives have been developed in different formulations like solid, semisolid and liquid formulations that include; adhesive tablets(Schor et al. 1983\&Davis et al. 1999), gel (Ishida et al 1983\&Bremecker et al. 1984), ointments (Sveinsson\& Holbrook 1993),patches (Guo 1984)and more recently films.(Kohda 1997)Solid formulation or tablets achieve bioadhesion through dehydration when placed directly onto the mucosal surface, but particle size is a limitation for adequate requirement of dosage. However bioadhesives containing micro particles make intimate contact with a larger mucosal surface area and can be delivered to less accessible sites. Smaller size ensures less chances of local irritation at the site of adhesion and the uncomfortable sensation of a foreign object within the oral cavity.(Batchelor 2004).

In the age of nano technology, nano particles hold the key as carriers of the oral delivery of poorly absorbable drugs. The adhesive properties of Gantrez were found to be stronger when folded as nano particles in solubilized form. (Irache 2005).

Drug delivery system is a composite wafer with surface layers possessing adhesive properties. The bulk layer consists of antimicrobial ants, biodegradable polymers and matrix polymers; these have been treatment of periodontal diseases. (Bromberg et al. 2000) Mucoadhesive lozenges may be used for slow and prolonged drugrelease within the mouth including antimicrobials, corticosteroids, local anaesthetics (semisolid) preparations have crosslinkedpolyacrylic acid and offer advantage of intimate contact and rapid release atabsorption site. Their limitations include the inability to deliver a measured dose of drug to the site. (Batchelor 2004).

The treatment of oral ulcerative lesions has been tremendously simplified by the use of bioadhesive flexible films (eg.Zilactiri) which provide a measured dose of drug at the site, thus doing away with creams and ointments. (Batchelor 2004) Also in terms of flexibility and comfort, they score over even oral gels as they circumvent the relatively shorter retention time on the mucosa and the salivatory wash factor. (Collins \&Deasy 1990) Moreover, the buccal film is able to protect the wound surface, thus reduce pain and also could treat oral diseases more effectively. (Peh\& Wong 1999) 


\section{Mucoadhesive agents}

Polymers which can adhere to either hard or soft tissues have been used for years in surgery and dentistry. (Drzewieckiet al. 1993 $\&$ Noordzijet al. 1994) The most commonly used synthetic polymers are alpha cyanoacrylates (e.g. butyl cyanoacrylate and 2-octyl cyanoacrylate),(Kutcher 2001)polyacrylic acid, hydroxypropyl methyl cellulose (HPC) and poly methacrylate derivatives. These are a group of compounds that polymerize in an exothermic reaction on contact with a fluid or with basic substances to form strong bonds. Based on the active ingredients these can be broadly described as follows:

Gums: Hydrogels formed by combination of natural gums, xanthurn and locust bean gums are used in bucco-delivery system. They offer an advantage of having high gel strength, sustained release and being safe.(Shojaei1998).

Hydroxypropyleellulose and Carhopol (HPC: CP): HPC shows slight adhesion but dissolve easily on the gel bed. Carbopol shows strong adhesion but is too hard in tablet formulation. The combination of HPC \& CP provides mucoadhesion as well as adequate softness for tablets preparation. (Satoh1998).

Caboxylatedpolyanions: They contain arylic acid and acryclamide random copolymers (P (AA-Co-AM) having about $80 \%$ of carboxyl groups in protonated form. Mucoadhesion occurs in these molecules through hydrogen bonding in order to achieve an adequate flexibility.(Park \& Robinson 1987).

Polycarbophils: They are basically water insoluble but have ability to swell due to presence of polyacrylic acid which cross-links with diviylglycol making its use for therapeutic purpose. Carbomer is one of the examples of a water soluble polymer of acrylic acid loosely cross-linked to allylsucrose.(Stephen et al.)

Polycations: These polymers interact with anionic sites on the mucin due to opposite charges. (Stephen et al. 1999).

Some naturally occurring polymers like hyaluronic acid and Chitosan have also been used as mucoadhesives. Chitosan is considered as ideal material for a mucoadhesionpolycationic polymer which is known to interact with molecules containing $\mathrm{n}$ - acetyl glucosamine, such as salivary lysozyme.(Needleman et al. 1997 \& Stephen et al. 1999).

\section{Application in dentistry}

Local delivery to tissues of oral cavity has a number of applications namely treatment of toothaches (Ishida 1982), Periodontal diseases (Collins et al. 1989) bacterial and fungal Infections, (Samaranayake\& Ferguson 1994), ulcerative oral mucosal (Nagai 1985) tooth movement with prostaglandins. (Nagai 1993)

1) Eugenol carried in mucoadhesive formulationof Hydroxypropylcellulose and Carbopol (I-IPC: CP) enables sustained release up to 8 hours-an advantage over conventional use, hence it enhances the potential of eugenol as local antibacterial, local analgesic and anaesthetic. (Jadhav et al. 2004).

2) Mucoadhesive microcapsule, nano-spheres, buccoadhesive tablets loaded with antibacterial drug can be directly placed in gingival crevice thereby increases the local availability of drug for a longer period of time e.g. tetracycline, metronidazole. It also helps in prevention of untoward reaction to systemic antibiotic therapy in terms of antibiotic resistance and side effects.( David et al. 1997).

3) Bioadhesive tablets containing fluoride are capable of delivering low levels of fluoride over long period of time and prevention of dental caries. (Bottenberg 1998).

4) Potassium nitrate bioadhesive gels have also been used with various rnbinations in patients with dentinal hypersensitivity.(Frechoso et al. 2003).

5) Cyanoacrylate tissue adhesives (2-OCA-2 octyl cyanoacrylate) may reduce pain and healing, time in patients with apthous ulcers. (Kutcher et al. 2001)
6) Buccoadhesives containing nystatin, miconazole, fungicidal agents have been used in different formulations with good results. (Irache et al. 2005).

7) Adhesive tablets prepared by compression moulding of mixed powders of cross linked polyacrylic acid and hydroxypropyl cellulose, absorbed with citrus oil and magnesium salt has been used for the treatment of oral ulcers. These tablets adhere well to the mucosal tissue and gradually disintegrate in 8 hours releasing the citrus and magnesium after a period of 2 hours. (Mizrahi 2004).

8) Solution containing bioadhesive polymers like sodium carboxymethyl cellulose (e.g. luborant antigen, saliveze) have for many years in patients with xerostomia. These artificial formulation have been used providing good lubrication thereby alleviating patients symptoms of dry mouth.(Mizrahi 2004).

9) Carbomer solutions have been used as artificial tears in patients with xeropthalmia secondary to sjogren syndrome and found to be a good substitute for lubrication. They adhere to the eye surface providing a good lubricating surface.(Batchelor 2004).

10) Topical application of bioadhesivechlorhexidine gel to Surgical wounds during the postoperative week may decrease the incidence of alveolar osteitis after extraction of mandibular third molars. (Hita-Iglesias et al. 2008)compliance in daily use of oral antiseptics can probably be enhanced scribing easily applied bioadhesive tablets which slowly release chlorhexidine. This formulationcan also be used in patients who face difficulties in rinsing, or performing mechanical plaque control.(Decker et al. 2005).

11) Lidocaine-containing bioadhesive anesthesia was system delivering topical found to be highly effective pain/discomfort arising from needle sticks, in alleviating with and without concomitant injection, and select scaling and root planing, procedures. This type of topical drug delivery may prove to be highly useful in allaying patient anxieties and fear of select dental procedures. (Chen et al. 2001 \&Taware et al. 1997).

\section{Conclusion}

In the present article, we have merely touched the tip of the iceberg as regards usage and application of bioadhesive drug delivery system in dentistry is concerned. In India, mucoadhesive formulations and its usage in other branches of medicine is quite prevalent; however, formulations available in treating oral technologies mucosal lesions are still lacking. The technologies described here represent only a small fraction of the development of drug delivery systems and a few of them are still at the experimental level. The safety and efficacy of current systems can be improved if their delivery rate, biodegradation, and site-specific targeting can be predicted, monitored, and controlled. Some other processes, which under development, include aerosol inhalation devices, forced-pressure injectibles, and biodegradable polymers specifically designed for therapy. With the help of rapid advances in biotechnology, and chemical engineering, it will be possible for researchers toobtain drug delivery systems with minimum side effects and maximum effectiveness.

\section{References}

[1] Amir H. Shojaei. Buccal Mucosa - As A Route for Systemic Drug Delivery: A Review. J Pharm PharmaceutSci (www.ualberta.ca/csps); 1(1):15-30, 1998.

[2] Anders R and Merkle H. Evaluation of laminated mucoadhesive patches for buccal drug delivery. Int. J. Pharm. 1989; 49:231-240. http://dx.doi.org/10.1016/0378-5173(89)90347-5.

[3] Barsuhn C.L, Olanoff L.S, Gleason D.D, AdkinsE.L, Ho, N.F. Human buccal absorption of flurbiprofen. Clin. Pharmacol. Then 1988 44:225-231. http://dx.doi.org/10.1038/clpt.1988.141. 
[4] Bhaskara J, Xiaoling L and Gary C. Recent Advances in mucoadhesive drug delivery systems. In Drug Delivery: Polymers-Business Briefing: Pharmatech. pp: 194-196, 2003.

[5] Jadhav B, Khandelwal K, Ketkar A, Pisal S. Formulation and evaluation of mucoadhesive tablets containing eugenol for the treatment of periodontal diseases. Drug Development and Industrial Pharmacy. 2004 Dec; 30 (2):195-203. http://dx.doi.org/10.1081/DDC$\underline{120028715}$.

[6] Mizrahi B, Golenser J, Wolnerman J, Domb A: Adhesive tablet effective for treating canker sores in humans. Journal of Pharmaceutical Sciences.2004 ; $\quad$ 93):2927-2935 http://dx.doi.org/10.1002/jps.20193.

[7] Bottenberg P, Bultmann C, GrAnber HG. Distribution of fluoride in the oral cavity after application of a bioadhesive fluoride-releasing ablct. J Dent Res. 1998 Jan; 77(1):68 72.http://dx.doi.org/10.1177/00220345980770010701.

[8] Bremecker K, Strempe H and Klein G. Novel concept for a mucosal adhesive ointment. J Pharm Sci. 1984; 73:548-552. http://dx.doi.org/10.1002/jps.2600730429.

[9] Bromberg LE, Braman VM, Rothstein DM et al. Sustained release of silver from peridontal wafers for the treatment of periodontitis. J. Control Release. 2000; 68:63-77. http://dx.doi.org/10.1016/S01683659(00)00233-9.

[10] Carr MP and Horton JE. Evaluation of a transoral delivery system for topical anesthesia. J Am Dent Assoc. 2001 Dec; 132(12):1714-9. http://dx.doi.org/10.14219/jada.archive.2001.0127.

[11] Chen W-G and Hwang GC-C. Adhesive and in vitro release characteristics of propranolol bioadhesive disc system. Int J Pharm 1992; 82(1-2):61-66. http://dx.doi.org/10.1016/0378-5173(92)90072-A

[12] Collins A.E and Deasy P.B, Bio-adhesive lozent2e for the improved delivery of cetylpyridinium chloride. J. Pharm. Sci.1990:79:116119. http://dx.doi.org/10.1002/jps.2600790208

[13] Collins A.E, Deasy P.B, Mac Carthy D.J. and Shanley D.B. Evaluation of a controlled release compact containing tetracycline hydrochloride bonded to tooth for the treatment of periodontal disease. Int. J. Pharm. 1989; 51:103-114. http://dx.doi.org/10.1016/03785173(89)90244-5

[14] David J, Woolfson A, Brown A and Neill M. J Control Release. 1997 Nov; 49 (1):71-79. http://dx.doi.org/10.1016/S01683659(97)00060-6.

[15] Davis S.S, Daly P.B, Kennerley J.W, Frier M, Hardy J.G. and Wilson C.G. Design and Evaluation of Sustained Release Formulations for Oral and Buccal Administration, In: Bussmann, Dries, R.R. and Wagner, W. (eds), Controlled Release formance. Int J Pharm 1999 177(2):201-209.

[16] Decker EM, Von Ohle C, Weiger R, Wiech I, Brecx M. A synergistic chlorhexidine/chitosan combination for improved antiplaque strategies. J Periodontal Res. 2005; oct; 40(5):373377.http://dx.doi.org/10.1111/j.1600-0765.2005.00817.x.

[17] Elkayam R, Friedman M, Stabholz A, Soskolne A, Sela M.N and GolubL.Sustained release device containing minocycline for local treatment of periodontal disease. J Control. Rel 1988; 7:231-236.

[18] Epstein JB, Truelove EL. Topical cyclosporine in a bioadhesive for treatment of oral lichenoid mucosal reactions: an open label clinical trial. Oral Surg Oral Med Oral Pathol Oral RadiolEndod. 1996 Nov; 82(5):532-6.http://dx.doi.org/10.1016/S1079-2104(96)80198-3.

[19] Frechoso SC, MenA@indez M, Guisasola C, Arregui I, Tejerina JM Sicilia A. Evaluation of the efficacy of two potassium ritratebioadhesive gels $(5 \%$ and $10 \%)$ in the treatment of dentinehypersentivity. A randomized clinical trial. J ClinPeriodontol 2003.30(4):315-320.

[20] Galey WR, Lonsdale HK, Nacht S. the in vitro permeability of skin and buccal mucosa to selecteddrugs and tritiated water. J Invest. Dermatol.1976; 1747.ep12598596

[21] Gandhi R and Robinson J. Oral cavity as a site for bioadhesive drug delivery. Adv. Drug Del. Rev. 1994; 13:43 74.http://dx.doi.org/10.1016/0169-409X(94)90026-4.

[22] Guo G H. Bioadhesive polymer buccal patches for buprenorphine controlled delivery: Formulation in vitro adhesion and release properties. Drug DevInd Pharmacy. 1994; 20:2819-2821. http://dx.doi.org/10.3109/03639049409042682.

[23] Han. RY, Fang JY, Sung KC, Hu OYP. Mucoadhesivebuccal disks for novel nalbuphine formulation prodrugontrolled delivery: Effect of variables on drug release and mucoadhesive per-formance. Int J Pharm 1999; 77(2):201-209. http://dx.doi.org/10.1016/S03785173(98)00343-3.

[24] Hannah Batchelor. Novel Bioadhesive formulations in drug delivery. In: The drug delivery companies report autumn winter 2004. pp. $16-18$.
[25] Harris D, Robinson J.R. Drug delivery via the mucous membranes of the oral cavity. J. Pharm. Sci. 1992; 81:1-10. http://dx.doi.org/10.1002/jps.2600810102.

[26] Hita-Iglesias P, Torres-Lagares D, Flores-Ruiz R, Magallanes-Abad $\mathrm{N}$, Effectiveness of chlorhexidine gel versus chlorhexidine rinse in reducing alveolar osteitis in mandibular third molar surgery. $\mathrm{J}$ Oral Maxillofac Surg. $2008 \quad$ Mar; 66(3):441-5. http://dx.doi.org/10.1016/j.joms.2007.06.641.

[27] Ishida M, Nambu N. and Nagai T. Highly viscous gel ointment containing Carbopol for application to the oral mucosa. Chem Pharm Bull.1983; 31:4561-4564. http://dx.doi.org/10.1248/cpb.31.4561.

[28] Ishida M, Nambu N, and Nagai T. Mucosal dosage form of ocaine for toothache using hydroxypropyl cellulose and carbopol, Chem. Pharm. Bull.1982;30:980-984.http://dx.doi.org/10.1248/cpb.30.980.

[29] John D Smart. The basics and underlying mechanism of mucoadhesion-mucoadhesve Polymers: Strategies, Acheivements and Future Challenges. 2005; Vol 57(11).

[30] Irache J, Maria Huici, Monica Konecny, Socorro Espuelas, Miguel Angel Campanero and Pau Arbos. Bioadhesive Properties of Gantrez Nanoparticles. Molecules 2005; 10:126-145. http://dx.doi.org/10.3390/10010126.

[31] Kohda, Y., Kobayashi, H., Baba, Y., Yuasa, H..Ozeki, T., Kanaya, $\mathrm{Y}$ and Sagara, E., Controlled release of lidocaine from buccal mucosa-adhesive films with solid dispersion. Int J Pharm. 1997; 158:147-155. http://dx.doi.org/10.1016/S0378-5173(97)00241-X.

[32] KokKhiangPeh, Choy Fun Wong. Polymeric Films as Vehicle for Buccal Delivery: Swelling, Mechanical, and Bioadhesive Properties. J Pharm PharmaceutSci (www.ualberta.ca/--csps). 1999.2(2):53-61.

[33] Kutcher M, Ludlow M, Samuelson A, Campbell T, Pusek T. Evaluation of a bioadhesive device for the management of aphthous ulcers. JADA, March 2001; 132:368-76. http://dx.doi.org/10.14219/jada.archive.2001.0180.

[34] Michael U Adikwu. Mucins and their potentials. Tropical Journal of Pharmaceutical Research. 2006 Dec; 5(2):581-582.

[35] Petelin M, Pavlica Z, Bizimoska S, Sentjurc M. In vivo study of different ointments for drug delivery mucosa by EPR oximetry. International Journal of Pharmaceutics. 2004; 270: $83-$ 91.http://dx.doi.org/10.1016/j.ijpharm.2003.10.030.

[36] Castionis N, Baehni P and Gurny R. Current status in oral fluoride pharmacokinetics and implications for prophylaxis against European Journal of Pharmaceutics Biopharmaceutics. 1998 Mar; 45(2):101-111.http://dx.doi.org/10.1016/S0939-6411(97)00083-0.

[37] Nagai T, Machida .Advances in drug delivery: Mucosal adhesive dosage forms. Pharm Int 1985; 6(8):196-200.

[38] Nagai T, Machida Y. Buccal delivery systems using hydrogels. Adv Drug Delivery Rev 1993; 11(1-2):179-191. http://dx.doi.org/10.1016/0169-409X(93)90032-Y.

[39] Nagai T.Adhesive topical drug delivery system, J. Control. Rel 1985; 2:121-134.http://dx.doi.org/10.1016/0168-3659(85)90038-0.

[40] Needleman IG, Smales FC, Martin GP. An investigation of caries and bioadhesion for periodontal and oral mucosal drug delivery. J ClinPeriodontol. 1997 Jun; 24(6):394400.http://dx.doi.org/10.1111/j.1600-051X.1997.tb00203.x.

[41] Noordzij JP, Foresman PA, Rodeheaver GT, Quinn JV, Edlich RF. Tissue adhesive wound repair revisited. J Emerg Med 1994; 12:645-9. http://dx.doi.org/10.1016/0736-4679(94)90417-0.

[42] Park H and Robinson JR. Mechanisms of mucoadhesion of poly (acrylic acid) hydrogels, Pharm. Res. 1987; 4:457-464 http://dx.doi.org/10.1023/A:1016467219657.

[43] Park CR, Munday DL. Development and evaluation of a b phasic buccal adhesive tablet for nicotine replacement therapy. Int J Pharm 2002; 237(1-2):215-226. http://dx.doi.org/10.1016/S03785173(02)00041-8.

[44] Pimlott S.J, Addy M. A study into the mucosal absorption of osorbidedinitrate at different intraoral sites. Oral. Surg, Oral. Med. Oral. Pathol. 1985; 59:145-148.http://dx.doi.org/10.1016/0030 4220(85)90006-4.

[45] Quinn Drzewiecki AE, Li MM, et al. A randomized, controlled a tissue adhesive with suturing in the re air of $\mathrm{p}$ pediatric facial lacerations. Ann Emerg Med 1993; 9:1130-5 http://dx.doi.org/10.1016/S0196-0644(05)80977-1.

[46] Samaranayake L and Ferguson M. Delivery of antifunQa1 agents to the oral cavity, Adv. Drug Del. Rev. 1994; 13:161-179. http://dx.doi.org/10.1016/0169-409X(94)90032-9.

[47] Satoh K, Takayama K, Machida Y, Suzuki Y, Nakagaki M. Nagai T. Factors affecting the bioadhesive property of tablets consistingof hydroxypropyl cellulose and carboxyvinyl polymer. Bull 1989; 37(5):1366-1368. 
[48] Schor J.M, Davis S.S, Nigalaye A and Bolton S. Sudarintransmucosal tablets. Drug DevInd Pharmacy.1983; 9:1359-1377. http://dx.doi.org/10.3109/03639048309046323.

[49] Scrivener CA, Schantz CW. J Am Dental Assoc. 1947; 35:644-647. http://dx.doi.org/10.14219/jada.archive.1947.0306.

[50] Senel S, Hincal AA. Drug permeation enhancement via buccal route: Possibilities and limitations. J Controlled Release 2001; 72(1-3):133-144. http://dx.doi.org/10.1016/S0168-3659(01)002693.

[51] Squier CA and Hall BK. The permeability of mammalian nonkeratinized oral epithelia to horse radish peroxidase applied in vivo and in vitro, Arch. Ural Biol., 29:45-50, 1984.http://dx.doi.org/10.1016/0003-9969(84)90041-4.

[52] Squier C.A. and Wertz P.W. Structure and function of the oral mucosa and implications for drug delivery, In M.J. Rathbone (ed.) Oral mucosal Drug Delivery, Marcel Dekker, Inc., New York, New $26,1996$.

[53] Squier C.A, Cox P, and Wertz P.W. Lipid content and water permeability of skin and oral mucosa. The J. Invest. Dermat. 1991; 96 : 123-126, http://dx.doi.org/10.1111/1523-1747.ep12515931.

[54] Stephen E, Hardingt S.S, Deacon M andFiebrig I. Biopolymer Mucoadhesive biotechnology and Genetic Engineering Reviews. Vol. 16, April, 1999.

[55] Sveinsson. S.J. and Holbrook, P.W., Oral' mucosa adhesive ointment containing, liposomal corticosteroid. Int J Pharm. 1993: 95:105-109. http://dx.doi.org/10.1016/0378-5173(93)90396-W.

[56] Taware CP, Mazumdar S, Pendharkar M, Adani MH, Devarajan PV. A bioadhesive delivery system as an alternative to infiltration anesthesia. Oral Surg Oral Med Oral Pathol Oral RadiolEndod. 1997 Dec; $\quad$ 84(6):609-15.http://dx.doi.org/10.1016/S10792104(97)90360-7.

[57] Wertz P.W and Squier C.A. Cellular and molecular basis of barrier function in oral epithelium, Crit. Sys.1991, 8:237-269.

[58] Wong C.F, Yuen K.H and Peh K.K., Formulation and evaluation of controlled release Eudragitbuccal patches. Int J Phartn.19q: J78:11 22.

[59] Wodley J. bioadhesion: New possibilities for drug administration. 2001; 40 (2):77-84. 